\title{
The Intelligence Industry: Guiding the New Way of Industrial Innovation----Evidence from Hi-Tech Parks of PRD
}

\section{$\mathrm{Li}$ ZHOU}

School of Economics and Management, Zhaoqing University, City Zhaoqing, Guangdong Province 526061, China

\begin{abstract}
The research aims to find out the new driving force during the economic slowdown to fit the Chinese "new normal phase". Through case study in Hi-Tech parks of PRD, the research finds evidences to confirm that the emergence and boom of the intelligence industry is guiding the new way of industrial innovation either in manufacturing cities or special economic zone, which also suggests that four industries classification model has replaced the traditional one to better reflect the real conditions of modern industrial structure and manifest the times' feature and industrial sophistication.
\end{abstract}

KEYWORD: intelligence industry; four industries' classification model; industrial innovation; Hi-Tech parks

\section{INTRODUCTION}

Although the economic circle and government have not reached a consensus about four industries classification model, the intelligence industry formed with information industry and knowledge industry or other wisdom-intensive industries has already come into existence. The intelligence industry is in essence an aggregation of modern information technology, namely the intelligence application of information technology. Both information industry and intelligence industry have showed the obvious features of knowledge, technology and computer-focused industrial sector. Therefore, this thesis divides the current industries into four classifications: agriculture, industry, service industry and intelligence industry [6], see Figure 1.

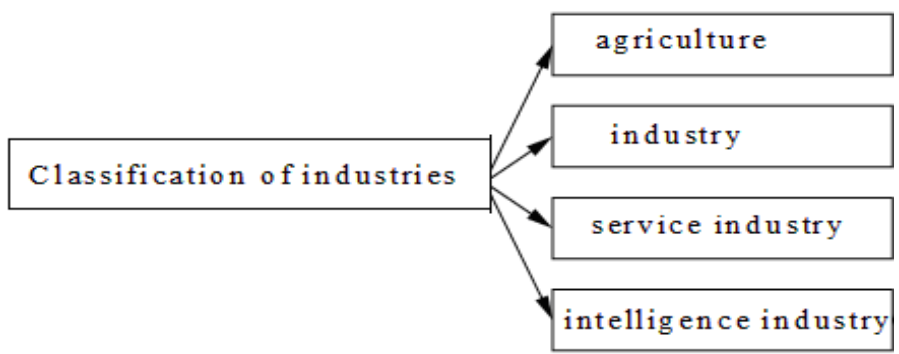

Figure 1. Classification of industries

\section{LITERATURE REVIEW}

\subsection{Fischer's industrial classification model}

According to Fischer (1935) [1], we can divide the multitudinous social professions into three main industries, namely the primary industry, the secondary industry and the tertiary industry. Fischer' industrial classification model is based on subject of labor and its processing sequence, taking economic development of industrial era as its realistic background, and considering the difference among processing objects and sequence of processing labors as its major classification principles.

Fischer's industrial classification is widely accepted by government and economic circle, and Chinese statistical department has also used this classification method since 1985. However, the practice proves that Fischer classification method has severe defects which have become more and more evident with the development of society and technology. The problems are mainly manifested in the classification of the tertiary industry.

According to Fischer's classification of industries, heterogeneous social professions are incorporated into the tertiary industry except the agriculture and industry in general meaning, which has caused the wide difference in professions and profession nature within the tertiary industry.

\subsection{Porat's industrial classification model}

The invention and application of computer is the symbol of quaternary industry. From the second to 
the fourth industrial revolution, computer and internet expanded the physical and virtual space of human existence and development, broke the region limits of economic transaction and cooperation, and innovated the new way of economic intercourse and people's life style.

Information economist Mac Uri Porat (1977) first proposed the four-industries classification model of national economy, namely the agriculture, the industry, the service industry and the information industry [8], in which information industry was incorporated into the quaternary industry and was separated from service industry with its independent industrial features and outstanding value.

\subsection{Modern industrial classification models}

Chinese scholar Zhuang Yizhao (2009) and other experts tended to redefine the Fischer' definition about the tertiary industry [10]. They believed that Fischer and his followers had defined some simple and explicit things for the primary and secondary industry, but defined a pocket of sundry goods for the tertiary industry. With the development of industry, this pocket of sundry became more and more puzzling and unsatisfying. Therefore, it needs to be poured out and rearranged clearly.

According to Zhuang Yizhao, the intelligence industry means using human's wisdom to research, create, produce, management visible or invisible intelligence products to meet the social demand. Intelligence industry is a collection of education, training, consultation, planning, advertisement, design, software, animation, film and television, art, science, law, accountant, news, publication sets and other similar professions. According to the Fischer's traditional industrial classification, the intelligence industry belonged to the high-end parts of the tertiary industry. While Zhuang Yizhao proposed that intelligence industry should be separated from the tertiary industry and form an independent industry because it has become more and more important in national economy no matter in theory or in practice.

Larry H.P. Lang's (2012) classification of industries suggests that the national economy is composed of agriculture, industry, service industry and intelligence industry [5]. Larry H.P. Lang called the intelligence industry the quaternary industry and believed that the intelligence industry is a brand-new industry which has made other professions more efficient. The emergence of intelligence industry has already profoundly influenced the traditional manufacturing industry and service industry.

This so called quaternary industry has already become an important constituent of national innovation strategy in US by enormously promoting the industrial efficiency and value chain. According to Larry H.P. Lang, intelligence industry has been introduced into American manufacturing industry for more than 10 years, and has achieved more than 50\% increase in its output value and $20 \%$ increase in its workers' efficiency. Therefore, promoting the traditional industry and upgrading the traditional market by utilizing automated technology and advanced network would be the focus in Chinese future development.

Representative viewpoints about industrial classification see Table 1.

Table1. Representative viewpoints on industrial classification

\begin{tabular}{|l|l|l|}
\hline Industrial classification & Representative scholars & Industries \\
\hline Three industries model & Fischer (1935) & Agriculture, industry, service industry \\
\hline \multirow{2}{*}{ Four industries model } & Mac Uri Porat (1977) & agriculture, industry, service industry, information industry \\
\cline { 2 - 3 } & Larry H.P. Lang (2012) & agriculture, industry, service industry, intelligence industry \\
\hline Five industries model & Zhuang Yizhao (2009) & $\begin{array}{l}\text { Agriculture, industry, service industry, information industry, } \\
\text { intelligence industry }\end{array}$ \\
\hline
\end{tabular}

\section{THE STRATEGIC MEANING OF INTELLIGENCE INDUSTRY}

The intelligence industry has changed the way of production and people's life style by grafting itself onto different industries to enhance productive efficiency and increase the added value of products and services, which has also given people a hopeful future as a new turn of industrial evolution.

First, the intelligence industry refers to various types of social professions involved in the reproduction of wisdom products, which helps promote traditional competitive industries by transforming the industrial structure from laborintensive to capital-intensive, knowledge-intensive and technology-intensive [2]. The rapid development and popularization of informationization and intellectualization, and the boom of industrial design, modern logistics, technical service etc. have already become a leading force in the industrial promotion and upgrading.

Second, the intelligence industry helps people reduce the excessive resource consumption and environmental pollution. So long as the production sectors reach a consensus, people are more willing to invest and consume intelligence industry and its 
products without undertaking a higher cost in the initial period [9].

Third, the intelligence industry urges the manufacturing industry to extend to both sides of the "smiling curve". In the rear end, namely the brand marketing link, intelligence industry enhances the quantity of enterprises with independent brands through systems engineering. In the front end, namely the research, development and design link, intelligence industry promotes the quantity of patent application and authorization. Through the reorganization of the industrial gene, traditional manufacturing can realize the substitution of material capital, and transfer to depend upon the excavation, the refinement, the condensation of human wisdom, including creativity, design, and intellectualization to realize the regional sustainable development.

\section{EVIDENCE FROM THE HIGH-TECH PARKS OF PRD}

\subsection{The Next Generation Internet Industry Plan of Shenzhen High-tech Park}

The high-tech Park in Shenzhen takes the internet industrial cluster as its entrepreneurial and innovation direction, which preferentially develop the networking industry, top software industry, triple play industry, electronic commerce industry and cloud computing industry. In 2013, there were more than 1023 enterprises within the internet industrial cluster, covering 264 high-tech enterprises and 124,800 personnel. The cluster insists on promoting its ability of independent research and development. The internet enterprises applied for 3855 patents, including 2784 invention patents and 1398 authorized patents. The R\&D expenditure of 606 enterprises comprises occupies more than $10 \%$ of their sales volume [4].

\subsection{The Pearl River Delta Design Valley of Foshan Hi-tech Park}

The intelligence industry has become the source and core competitiveness of manufacturing industries. As an important manufacturing city of PRD, Foshan is actively developing the creative industries especially industrial design to seize the commanding point of the new turn of regional competition. The Pearl River Delta Design Valley (herein after refereed to as "PRDDV") is to build an industrial design base which service as a public platform to help the local enterprises realize their industrial upgrading and reforming. Through construction of platform and gathering talented people, PRDDV strengthens the open cooperation among industries, universities and research institutes through joint stock system and setting up industrial design research institutes to realize the product innovation and provide the hatching service for industrial design organizations. PRDDV intends to build a nationallevel demonstration base of industrial design so as to impel the industrial design with Chinese characteristics by multi-layers wisdom integration and collaboration [3].

\subsection{The wisdom city, intelligent manufacturing plan of Dongguan Science Park}

Dongguan, another important manufacturing city of PRD, proposed smart city, intelligent manufacture plan to improve its industrial structure. Sungshanlake Science Park introduced the 3D printing technology, the holographic laser technology, the cloud computing, the smart cloud, the new energy vehicle and other technologies to guide the trend of its industrial innovation. As a research and development base of new energy vehicle, Sungshanlake Science Park has established the research and development platform for three series of finished automobile, and three series of core spare part. And more, it has built up the demonstration base of new energy vehicle for professional, new and lightweight electrical vehicle to guide and support the pooling of innovation factors [7].

\section{CONCLUSION}

The innovation of industrial classification should be studied with a dynamic viewpoint to fit the "new normal" phase. When people realize that the technology advancement can promote the economic growth, they will seek a new industrial evolution during the economic slowdown. The innovation of industrial classification is a reasonable result under a certain historical conditions and economic developing stage. Intelligence industry featured by cloud computing and the large data infrastructure is not merely the IT technology and enterprise supporting platform, it is guiding the new direction of industrial innovation with service pattern innovation and business model innovation to reach a new development summit.

\section{REFERENCES}

[1] Fischer.A.G.1989.Confrontation between security and progress. Beijing: China Renmin University Press.

[2] Greunz L. 2004.Industrial structure and innovationevidence from European region. Journal of Evolutionary Economics. 14(5): 563-592.

[3] Huiting Chen. On Foshan's innovation capacity, Foshan Daily, 2014-11-24.

[4] Jing Xie. Next-generation internet industrial cluster in Shenzhen, Shenzhen Business Report. 2013-07-04. 
[5] Larry H.P. Lang.2012.Intelligence Industry will become the quaternary industry. Zhejiang Finance 2012-12-24.

[6] Li Zhou. 2013. A research on the integrative development of cultural creativity industry with other three industries. Beijing: Enterprise Management Press.

[7] Ning Wang. Dongguan intelligence city plan enters a new turn of upsurge. Nan Fang Daily, 2014-11-12.

[8] Porat M. U. 1987. The information economy: definition and measurement. Beijing: China Prospect Publishing House.

[9] Vanhaverbeke W, Van de Vrande V, Chesbrough H. 2008. Understanding the advantages of open innovation practices in corporate venturing in terms of real options. Creativity and Innovation Management. 17(4): 251-258.

[10] Yizhao Zhuang. 2009. About intelligence industry. Intelligence Net. http://www.witpark.com/2009-4-17. 